\title{
Classical risk factors of cardiovascular disease among Chinese male steel workers: a prospective cohort study for 20 years
}

\author{
Jingfeng Ji', Enchun Pan ${ }^{1}$, Jianxin $\mathrm{Li}^{1}$, Jichun Chen ${ }^{1}$, Jie Cao ${ }^{1}$, Dongling Sun ${ }^{1}$, Xiangfeng Lu', Shufeng Chen ${ }^{1}$,
} Dongfeng $\mathrm{Gu}^{1}$, Xiufang Duan ${ }^{1}$, Xigui $\mathrm{Wu}^{1}$ and Jianfeng Huang ${ }^{2^{*}}$

\begin{abstract}
Background: Cardiovascular disease (CVD) constitutes a major public health problem in China and worldwide. We aimed to examine classical risk factors and their magnitudes for CVD in a Chinese cohort with over 20 years follow-up.

Methods: A cohort of 5092 male steelworkers recruited from 1974 to 1980 in Beijing of China was followed up for an average of 20.84 years. Cox proportional-hazards regression model were used to evaluate the risk of developing a first CVD event in the study participants who were free of CVD at the baseline.

Results: The multivariable-adjusted hazard ratio (HR) associated with every $20 \mathrm{mmHg}$ rise in systolic blood pressure (SBP) was 1.63 in this Chinese male population, which was higher than in Caucasians. Compared to non-smokers, men who smoked not less than one-pack-a-day had a HR of 2.43 (95\% confidence interval [CI], 1.75-3.38). The HR $(95 \% \mathrm{Cl})$ for every $20 \mathrm{mg} / \mathrm{dl}$ increase in total serum cholesterol (TC) and for every point rise in body mass index (BMI) was 1.13 (1.04-1.23) and 1.06 (1.02-1.09), respectively.

Conclusions: Our study documents that hypertension, smoking, overweight and hypercholesterolemia are major conventional risk factors of CVD in Chinese male adults. Continued strengthening programs for prevention and intervention on these risk factors are needed to reduce the incidence of CVD in China.
\end{abstract}

\section{Background}

Cardiovascular disease (CVD) constitutes a major public health problem in China [1] and worldwide [2]. Classical risk factors for coronary heart disease (CHD) and stroke have been identified [3,4], such as high blood pressure, tobacco smoking, hypercholesterolemia, obesity and age. The roles of major cardiovascular risk factors in the development of CHD or stroke are well established in Western populations. While for Chinese, data are less extensive, especially lack of over twenty years prospective cohort study to investigate the magnitude of classical risk factors for CVD. Previous studies have proved that the profile of CVD among Chinese is much different from among Caucasians. Compared with Western populations, the incidence and mortality rates of

\footnotetext{
*Correspondence: jianfhuang@sina.com

${ }^{2}$ Cardiovascular Institute and Fu Wai Hospital, Chinese Academy of Medical

Sciences and Peking Union Medical College, Beijing, China

Full list of author information is available at the end of the article
}

cerebrovascular disease were much higher than those of CHD in Chinese populations [5]. Risk factors of developing acute coronary syndrome, ischemic or hemorrhagic stroke were explored in a multi-provincial cohort with 10 years follow-up [6], and results of classical risk factors for CHD and stroke in our cohort with 13.5 years follow-up were reported previously $[7,8]$, however, it is unclear the profile and magnitude of classical risk factors for CVD in a Chinese cohort with over 20 years follow-up, and whether it was different from that in Western populations. Therefore, we aimed to examine classical risk factors and their magnitudes for CVD in this Chinese cohort.

\section{Methods}

Study population

A prospective cohort study of CVD has been conducted in the Beijing Iron and Steel Complex since 1974. Details of the study population and methods for the

\section{C) Biomed Central}


cohort have been published elsewhere [7]. In 3 separate waves of recruitment (1974, 1979, and 1980), 5298 male workers(aged 18 to 74 years) from 7 factories of the Beijing Iron and Steel Complex attended health check, and 5092 participants were free of CVD at the baseline. The project health practitioners conducted follow-up until 2001. By the year of 2001, 106 participants were lost to follow-up and 4986 participants were included in our cohort.

\section{Baseline examination}

In the 1974, 1979, and 1980 surveys, clinical evaluation and laboratory measurements were performed with the same protocol. Demographic lifestyle information and measurements including blood pressure, total cholesterol (TC), weight, and height were obtained. Smoking and drinking behaviors were collected by the interview. Blood pressure was measured in the right arm using a standard mercury sphygmomanometer with the subject in a sitting position. Hypertension was defined as systolic blood pressure (SBP) more than or equal to 140 $\mathrm{mmHg}$ and/or diastolic blood pressure (DBP) more than or equal to $90 \mathrm{mmHg}$. Pulse pressure (PP) was defined as $\mathrm{PP}=\mathrm{SBP}-\mathrm{DBP}$, and mean arterial pressure (MAP) was calculated from the standard equation MAP $=(2 / 3)$ $\mathrm{DBP}+(1 / 3)$ SBP (in $\mathrm{mmHg}$ ). The height and weight of each subject, wearing light clothes without shoes, were recorded. Body mass index (BMI) was calculated as weight $(\mathrm{kg}) /$ height $(\mathrm{m})^{2}$. TC was determined on the same single occasion from a fasting venous blood sample, using the enzyme regent method as our previous study reported [7]. Diabetes was not included in our analyses because only six persons reported diabetes at baseline.

\section{Follow-up data collection}

We carried out follow-up survey in 1982, 1987, 1993 and 2001, respectively. By the year of 2001, 2.1\% of subjects were lost to follow-up. The average follow-up time was 20.84 years. If participants could not be followed up by a way of face-to-face or telephone interview, their relatives or colleagues were contacted for information. Because surveillance system of CVD has been set up since 1960s in Beijing Capital Steel and Iron Company and most of steelworkers were treated in Capital Steel Hospital, self-reported outcomes could be confirmed by reviewing disease report cards and hospital records. When participants reported CVD, their hospital records were verified by physicians from the company hospital, and by physicians from the cardiovascular institute and Fu Wai hospital, Chinese Academy of Medical Sciences. For all fatalities, death certificates were obtained to confirm cause of death.
This study defined CVD as a composite of CHD events (including acute myocardial infarction [AMI], coronary sudden death and other coronary death) and cerebrovascular events (including ischemic stroke and hemorrhagic stroke), but not peripheral vascular disease. Coronary deaths included deaths caused by AMI, heart failure and cardiac arrest.

This research was carried out in compliance with the Helsinki Declaration. Ethics committees in Cardiovascular Institute and Fuwai Hospital, Chinese Academy of Medical Sciences approved the study with a reference number 110-1.

\section{Statistical Analyses}

This analysis was performed with the 4238 individuals who had no missing values for the variables under investigation. We compared the baseline characteristics of the remaining population with that of the original population. Cox proportional-hazards regression model was used to estimate the hazard ratios (HRs) of CVD incidence for preventable risk factors. Covariates included in Cox models were age, hypertension, cigarette smoking, TC, and BMI. Participants who had both CHD and stroke event were censored after their first CVD event in Cox model. Considering the problem of collinearity, blood pressure indices (SBP, DBP, MAP and PP) were separately included in the multivariate regression model with other risk factors. The cut points of adult underweight, overweight and obesity according to BMI were defined by the Chinese overweight and obesity prevention guideline [9] and the World Health Organization (WHO) classification [10], respectively. We also tested for interactions between each variable and age, and compared our results with the results of version two of the QRISK cardiovascular disease risk algorithm (QRISK2) [11].

The population-attributable risk (PAR) was also calculated to quantify the contribution of each independent modifiable risk factor on CVD using the following equation: $\mathrm{PAR}=[\mathrm{P} \times(\mathrm{RR}-1)] /[\mathrm{P} \times(\mathrm{RR}-1)+1]$, where $\mathrm{P}$ signifies the prevalence of the risk factor and $R R$ signifies the adjusted relative risk of CVD incidence [12]. Because the risk factor levels might change a lot during the last two decades in China, it wasn't very convincible to use the prevalence rates of these risk factors at the baseline. Therefore we used the prevalence in our study and the prevalence for urban male adults (18 years of age or older) in the National Health and Nutrition Survey 2002 $[13,14]$ to calculate the PAR. The HR from Cox regression models was used to estimate relative risk (RR). The statistical package SPSS (version 12.0, Chicago, USA) was used for data analysis. 


\section{Results}

Baseline Characteristics of the Study Population

The baseline characteristics of the original population and the remaining population in this analysis are presented in Table 1 . The remaining population was representative of the original population. During the followup, 391 subjects developed a first CVD event in the remaining population, including 255 cases of stroke and 136 cases of CHD events. A total of 599 deaths were reported, 240 persons died of CVD, 194 persons died of neoplasm and 165 persons died of other disease and injury.

\section{Multivariate analyses of classical risk factors}

Table 2 shows the results of the Cox regression analyses for the final model. There were continuous, graded increases in CVD risk either for every $20 \mathrm{mmHg}$ rise of $\mathrm{SBP}$, or for every $10 \mathrm{mmHg}$ rise of DBP. For the men with the highest level of blood pressure(SBP $\geq 180$ $\mathrm{mmHg}$ or DBP $\geq 100 \mathrm{mmHg}$ ) had the highest risk of CVD, and the HRs (95\% confidence interval [CI]) was 7.56(4.71-12.14) and 4.19(3.07-5.71), respectively. Compared to non-smokers, the multivariable adjusted HR of CVD was 2.43 (95\% CI, 1.75-3.38) for men who smoke more than or equal to one-pack-a-day. In multivariate analysis, there was an increased risk of CVD only in the group of TC category greater than or equal to $220 \mathrm{mg} /$ dL, with a HR of $1.42(95 \% \mathrm{CI}, 1.08-1.85)$.

Table 3 shows the results about BMI according to the WHO classification and the Chinese classification for underweight, normal weight, overweight and obesity. The average BMI in this study sample was $23.2 \mathrm{~kg} / \mathrm{m}^{2}$; $35.0 \%$ of participants were overweight (BMI $\geq 24 \mathrm{~kg} /$ $\left.\mathrm{m}^{2}\right)$, and $5.2 \%$ were obesity $\left(\mathrm{BMI} \geq 28 \mathrm{~kg} / \mathrm{m}^{2}\right)$. The HR for overweight and obesity was 1.24 (95\% CI, 1.01-1.52) and 1.37 (95\% CI, 0.96-1.97), respectively. When treated as a continuous variable, the HR for CVD was 1.16(95\% CI, 0.99-1.37) for 5 points rise of BMI (Table 4).

Table 4 also shows the comparison between the results of Chinese steelworkers cohort and the results of males from the derivation cohort of QRISK2 model. The most difference was that the HR of CVD associated with every $20 \mathrm{mmHg}$ rise in systolic blood pressure (SBP) in our study was much higher than result of QRISK2 model(1.63 vs. 1.19).

The PAR of hypertension, smoking, overweight (BMI $\geq 24 \mathrm{~kg} / \mathrm{m}^{2}$ ) and hypercholesterolemia (> $220 \mathrm{mg} / \mathrm{dl}$ or $5.7 \mathrm{mmol} / \mathrm{l}$ ) was $29.2 \%, 29.4 \%, 7.7 \%$ and $4.8 \%$, respectively for CVD when using the risk factors prevalence of our study. While using the prevalence rates of risk factors in urban men in the National Health and Nutrition Survey 2002, the PAR for hypertension, smoking, overweight and hypercholesterolemia was $20.8 \%, 22.7 \%$, $6.9 \%$ and $1.1 \%$, respectively.

\section{Discussion}

Since the Framingham heart study examined major risks of CVD in white American[15], a few studies at the population level in exploring different patterns of CVD risks between Chinese population and Caucasians have been reported[7,8,16,17], and risk scores for local population other than the Framingham score have subsequently been published[18,19]. Liu, et al [17] recalibrated the Framingham functions by using the mean values of risk factors and mean CHD incidence rate from Chinese Multi-Provincial Cohort Study (CMCS), given a much lower CHD incidence rate in China compared with that in Framingham, the United States. Our previous reports $[7,8]$ also indicated that stroke was more prevalent than CHD in China by a cohort with an average 13.5 years follow-up. Furthermore, application of recalibrated Framingham models for ischemic cardiovascular disease (including ischemic stroke and coronary events) significantly overestimated the CHD risk in another Chinese cardiovascular epidemiology cohort [16]. It is controversial whether a recalibrated Western risk function can be useful in China. Except that risk prediction using CMCS and PRC-USA risk coefficients differed from Framingham, there were differences between the two Chinese cohort studies as

Table 1 Baseline characteristics of the Beijing steel workers cohort

\begin{tabular}{lcccc}
\hline Variables & Entire cohort $(\mathbf{N}=\mathbf{4 9 8 6})$ & means \pm SD & Cohort used in this study (N = 4238) & means \pm SD \\
\hline Age $(\mathrm{yr})$ & 4975 & $45.08 \pm 7.82$ & 4238 & $44.91 \pm 7.93$ \\
\hline TC $(\mathrm{mg} / \mathrm{dl})$ & 4521 & $186.25 \pm 38.65$ & 4238 & $187.58 \pm 37.87$ \\
\hline BMI $\left(\mathrm{kg} / \mathrm{m}^{2}\right)$ & 4782 & $23.18 \pm 2.72$ & 4238 & $23.17 \pm 2.71$ \\
\hline $\mathrm{SBP}(\mathrm{mmHg})$ & 4976 & $123.26 \pm 18.86$ & 4238 & $122.89 \pm 18.67$ \\
\hline $\mathrm{DBP}(\mathrm{mmHg})$ & 4976 & $80.91 \pm 11.89$ & 4238 & $80.80 \pm 11.83$ \\
\hline PP $(\mathrm{mmHg})$ & 4976 & $42.34 \pm 11.78$ & 4238 & $42.09 \pm 11.77$ \\
\hline MAP $(\mathrm{mmHg})$ & 4976 & $95.03 \pm 13.49$ & 4238 & $94.83 \pm 13.37$ \\
\hline Hypertension (\%) & 4976 & 32.13 & 4238 & 31.69 \\
\hline Cigarette smoker $(\%)$ & 4932 & 73.44 & 4238 & 73.36 \\
\hline
\end{tabular}


Table 2 Multivariable adjusted hazard ratios for CVD according to different levels of major risk factors

\begin{tabular}{|c|c|c|c|c|c|c|c|}
\hline Variables & Range & CVD events & Number & Person-years & $\begin{array}{c}\text { Incidence (per } \\
1000 \text { person years) }\end{array}$ & HR & $95 \% \mathrm{Cl}$ \\
\hline \multirow[t]{5}{*}{$\mathrm{SBP}(\mathrm{mmHg})$} & $<120$ & 88 & 1712 & 35895 & 2.45 & 1 & - \\
\hline & 120-139 & 136 & 1641 & 33646 & 4.04 & 1.52 & 1.16-1.99 \\
\hline & 140-159 & 99 & 635 & 12451 & 7.95 & 2.48 & $1.84-3.36$ \\
\hline & 160-179 & 45 & 194 & 3465 & 12.99 & 3.59 & $2.47-5.24$ \\
\hline & $\geq 180$ & 23 & 56 & 831 & 27.68 & 7.56 & $4.71-12.14$ \\
\hline \multirow[t]{4}{*}{$\mathrm{DBP}(\mathrm{mmHg})$} & $<80$ & 75 & 1529 & 31955 & 2.35 & 1 & - \\
\hline & 80-89 & 111 & 1500 & 30971 & 3.58 & 1.49 & $1.11-2.00$ \\
\hline & $90-99$ & 96 & 751 & 15015 & 6.39 & 2.27 & $1.67-3.10$ \\
\hline & $\geq 100$ & 109 & 458 & 8347 & 13.06 & 4.19 & $3.07-5.71$ \\
\hline \multirow[t]{4}{*}{$\mathrm{PP}(\mathrm{mmHg})$} & $<35$ & 72 & 1099 & 23008 & 3.13 & 1 & - \\
\hline & $35-44$ & 136 & 1737 & 35663 & 3.81 & 1.15 & $0.87-1.54$ \\
\hline & $45-54$ & 93 & 909 & 18289 & 5.09 & 1.41 & 1.03-1.93 \\
\hline & $\geq 55$ & 90 & 493 & 9328 & 9.65 & 2.08 & $1.50-2.87$ \\
\hline \multirow[t]{4}{*}{ MAP $(\mathrm{mmHg})$} & $<83.34$ & 50 & 1112 & 23095 & 2.16 & 1 & - \\
\hline & 83.34-93.33 & 85 & 1335 & 27824 & 3.05 & 1.32 & $0.93-1.88$ \\
\hline & 93.34-103.33 & 85 & 918 & 18885 & 4.5 & 1.75 & $1.23-2.50$ \\
\hline & $\geq 103.34$ & 171 & 873 & 16484 & 10.37 & 3.49 & $2.51-4.86$ \\
\hline \multirow[t]{4}{*}{ Cigarette dosage (cigarettes/day) } & Non-smoker & 85 & 1126 & 23280 & 3.65 & 1 & - \\
\hline & $1-9$ & 89 & 1054 & 21334 & 4.17 & 1.37 & $1.02-1.85$ \\
\hline & $10-19$ & 153 & 1691 & 33991 & 4.5 & 1.47 & $1.12-1.92$ \\
\hline & $\geq 20$ & 64 & 367 & 7683 & 8.33 & 2.43 & $1.75-3.38$ \\
\hline \multirow[t]{4}{*}{$\mathrm{TC}(\mathrm{mg} / \mathrm{dl})$} & $<180$ & 128 & 1879 & 38362 & 3.34 & 1 & - \\
\hline & 180-199.9 & 90 & 931 & 18968 & 4.74 & 1.14 & $0.87-1.50$ \\
\hline & 200-219.9 & 77 & 682 & 13889 & 5.54 & 1.25 & 0.94-1.66 \\
\hline & $\geq 220$ & 96 & 746 & 15069 & 6.37 & 1.42 & $1.08-1.85$ \\
\hline BMI $\left(\mathrm{kg} / \mathrm{m}^{2}\right)$ & - & 391 & 4238 & & & 1.06 & $1.02-1.09$ \\
\hline
\end{tabular}

Adjusted for age, TC, BMI, SBP, and daily cigarette dosage.

Table 3 Two types of classification of adult underweight, overweight and obesity

\begin{tabular}{|c|c|c|c|c|c|c|c|c|}
\hline & BMI $\left(\mathrm{kg} / \mathrm{m}^{2}\right)$ & CVD events & Number & Person years & $\begin{array}{c}\text { Incidence (per } \\
1000 \text { person years) }\end{array}$ & HR & $95 \% \mathrm{Cl}$ & $P$ value \\
\hline \multicolumn{9}{|c|}{ The WHO classification +} \\
\hline Underweight & $<18.5$ & 5 & 99 & 1999 & 2.5 & 0.7 & $0.29-1.69$ & 0.43 \\
\hline Normal range & $18.5-24.9$ & 254 & 3151 & 64748 & 3.92 & 1 & - & \\
\hline Overweight & $\geq 25.0$ & 132 & 988 & 19541 & 6.76 & 1.25 & $1.00-1.55$ & $<0.05$ \\
\hline Pre-obesity & $25.0-29.9$ & 120 & 929 & 18450 & 6.5 & 1.22 & $0.97-1.52$ & 0.09 \\
\hline Obesity & $\geq 30.0$ & 12 & 59 & 1091 & 11 & 1.72 & $0.96-3.08$ & 0.07 \\
\hline \multicolumn{9}{|c|}{ The Chinese Classification $\neq$} \\
\hline Underweight & $<18.5$ & 5 & 99 & 1999 & 2.5 & 0.72 & $0.29-1.74$ & 0.46 \\
\hline Normal range & $18.5-23.9$ & 204 & 2655 & 54726 & 3.73 & 1 & - & \\
\hline Overweight & $\geq 24.0$ & 182 & 1484 & 56725 & 3.21 & 1.24 & $1.01-1.52$ & $<0.05$ \\
\hline Pre-obesity & $24.0-27.9$ & 145 & 1265 & 25398 & 5.71 & 1.21 & $0.97-1.50$ & 0.09 \\
\hline Obesity & $\geq 28.0$ & 37 & 219 & 4165 & 8.88 & 1.37 & $0.96-1.97$ & 0.09 \\
\hline
\end{tabular}

Adjusted for age, TC, BMI, SBP, and daily cigarette dosage.

† According to World Health Organization' web http://apps.who.int/bmi/index.jsp?introPage=intro_3.html

₹ According to Chinese overweight and obesity prevention guideline 
Table 4 Multivariable adjusted hazard ratios (95\% CI) for CVD from selected studies for men

\begin{tabular}{|c|c|c|c|c|}
\hline \multirow[t]{2}{*}{ Characteristics } & \multicolumn{2}{|c|}{ Chinese steelworkers cohort } & \multicolumn{2}{|c|}{ derivation cohort of QRISK2 model } \\
\hline & $\mathrm{HR}$ & $95 \% \mathrm{Cl}$ & $H R$ & $95 \% \mathrm{Cl}$ \\
\hline Age (5 years increase) & 1.29 & $1.18-1.40$ & 1.59 & $1.58-1.60$ \\
\hline SBP (20 mmHg increase) & 1.63 & $1.48-1.80$ & 1.19 & $1.17-1.20$ \\
\hline Current smoker & 1.54 & $1.21-1.97$ & 1.65 & $1.60-1.70$ \\
\hline $\mathrm{TC}$ & $1.13+$ & $1.04-1.23$ & $1.19 \neq$ & $1.18-1.20$ \\
\hline BMI $\left(5 \mathrm{~kg} / \mathrm{m}^{2}\right.$ increase $)$ & 1.16 & $0.99-1.37$ & 1.09 & $1.07-1.11$ \\
\hline Age* SBP interaction & 0.993 & 0.920-1.070 & 0.964 & $0.960-0.969$ \\
\hline Age $^{*}$ smoking interaction & 1.211 & $1.010-1.451$ & 0.932 & $0.922-0.942$ \\
\hline $\mathrm{Age}^{*} \mathrm{BMI}$ interaction & 0.955 & $0.929-0.981$ & 0.985 & $0.979-0.991$ \\
\hline
\end{tabular}

Adjusted for age, TC, BMI, SBP, and Current smoker. † TC for $20 \mathrm{mg} / \mathrm{dL}$ increase, $\neq$ For Cholesterol/HDL ratio

well. In fact, the magnitude of risk coefficients predicting CVD in Chinese adults are not established. Therefore this study adds important information regarding the epidemiology of CVD and its risk factors in China. Furthermore, to our knowledge, this cohort followed up for an average of 20.84 years is the longest Chinese cohort specified for CVD events.

Prevalences of hypertension, hypercholesterolemia, and obesity in our cohort were lower than that in Caucasian cohorts, such as the MONICA cohort in Augsburg, Germany, but the prevalence of hypertension was still higher than that in China National Nutrition and Health Survey 2002 (32\% vs. 20\%). Smoking was much more prevalent in our cohort. The smoking rate in our cohort (73.4\%) was similar with that of urban men from the PRC-USA cooperative study (71\%-78\%) [20], but higher than that for male adults who were 40 years of age or older in China National Hypertension Survey 1991(59.1\%) [21].

In this study, we focused on magnitude of classical risk factors for CVD. We also compared our results with the HRs of QRISK2 model in derivation cohort (Table 4). QRISK2 was a prospective cohort study conducted in a large UK primary care population (2.3 million people aged 35-74 with 140000 cardiovascular events) [11]. Although the QRISK2 model was derived mostly from European, there were still 22,013 south Asian and 19,792 from Chinese or other Asian or other ethnic groups among the overall population. Meanwhile, the characteristics of Chinese-English in derivation cohort of QRISK2 were similar with our baseline characteristics, for example, SBP (125.0 vs. $122.9 \mathrm{mmHg})$, BMI (23.4 vs. $\left.23.2 \mathrm{~kg} / \mathrm{m}^{2}\right)$ and age at entry $(49.0 \mathrm{vs}$. 44.9). Therefore, we compared the magnitude of classical risk factors in these two studies.

\section{Blood Pressure}

The HR (1.30, 95\% CI: 1.23-1.37) of CVD events for 10 $\mathrm{mmHg}$ rise in SBP in our cohort was higher than that
(1.19, 95\% CI: 1.17-1.20) in Caucasian study [11]. Our study indicated raised blood pressure is the leading preventable risk factor for CVD in the Chinese general population. There was a continuous graded increase in risk of CVD as blood pressure increased, with no evidence of a threshold value. This is consistent with the findings in the studies of Chinese and Asian population $[17,22,23]$. In QRISK2, there was an interaction between SBP and age on CVD. However, the interaction between SBP and age on CVD did not reach statistical significance in our study.

We also reported HRs of DBP, MAP and PP for every $10 \mathrm{mmHg}$ rise in the prediction of CVD. These four BP indices represent different clinical meanings. The Physicians' Health Study suggested that SBP, DBP, and MAP strongly predict CVD among men younger than 60 years[24], whereas most studies showed that PP is a more useful and independent predictor for the risk of CVD in older people[25-28].

\section{Smoking}

Cigarette smoking is another important risk factor of CVD for men in China because of its high prevalence. A nationally representative sample of Chinese adult cohort has reported RR of CVD for male cigarette smoker [29]. Though adjusted HRs for smoking in men of the Framingham Heart Study and the QRISK2 model were higher than that in our cohort (1.92 and 1.65 vs. 1.54) $[11,30]$, our result was similar to that of Chinese national hypertension surveys [29].

The dose-response relationship between tobacco smoking and HR of CVD was observed in our study (Table 2). The effect of cigarette smoking on cardiovascular health is evident even at the lowest levels of exposure in Western study [31]. Similarly, the HR was statistically significant in the lowest cigarette dosage group (1-9 cigarettes/day) in our cohort. Moreover, an interaction between age and smoking on CVD was identified in our study (Table 4), which was different from 
the result of QRISK2 model. This additive interaction indicated that Chinese male smokers would have extra risk of CVD with the increase of age, and also implicated that smoking cessation may provide more benefits for CVD prevention in China.

\section{Total Cholesterol}

A report indicated that $23.8 \%$ and $9.0 \%$ of the Chinese adult population have a total cholesterol level between $200 \mathrm{mg} / \mathrm{dL}$ and $239 \mathrm{mg} / \mathrm{dL}$ and $\geq 240 \mathrm{mg} / \mathrm{dL}$, respectively [32], which was similar with our results $(24.7 \%$ and $9.0 \%$ ). The multivariable adjusted $\mathrm{HR}$ of $\mathrm{TC}$ in our study was similar to that of Caucasians. However the baseline level of TC in our study was much lower than that in the Framingham study and QRISK study, the role of hypercholesterolemia for CVD in Chinese was not as high as in Caucasians.

With decreasing cholesterol levels, previous study reported a trend towards an increase in risk of hemorrhagic stroke [23]. Although $21.8 \%$ of the participants with the serum TC level below $160 \mathrm{mg} / \mathrm{dl}$, no such trend was detected in our current study (data not shown). Our result was consistent with the Heart Protection Study [33].

\section{Body Mass Index}

Although overweight and obesity were not included in the general CVD risk prediction model of the Framingham Heart Study [30], the impact of body mass index on the risk of CVD incidence was proven by many studies. European guidelines on cardiovascular disease prevention suggested that avoiding overweight or reducing existing overweight should be important in patients with established CVD as well as in high risk people [34]. BMI was used as a predictive parameter for CVD in QRISK and QRISK2 models. The magnitude of BMI for CVD in our cohort was even greater than that in QRISK2. In QRISK2, there was a negative interaction between BMI and age on risk of CVD (0.985, 95\% CI: 0.979-0.991), similar finding was found in our population (Table 4).

Participants of our study had a lower average BMI than those of most Caucasians studies $[4,11,19,35]$. For example, the average BMI in our study was $3.1 \mathrm{~kg} / \mathrm{m}^{2}$ lower than that of males in Framingham Heart Study. While there were positive associations between overweight and CVD either according to WHO definition or according to Chinese definition. However, using WHO classification might underestimate the number of obesity in Chinese population. In fact, there were only 59 participants (1.4\%) with BMI $\geq 30 \mathrm{~kg} / \mathrm{m}^{2}$ in our cohort. Using $24 \mathrm{~kg} /$ $\mathrm{m}^{2}$ and $28 \mathrm{~kg} / \mathrm{m}^{2}$ as the cut points for overweight and obesity in Chinese adults was recommended by the Chinese overweight and obesity prevention guideline, and was applied in many previous studies [36-38].
Overall, the role of overweight for CVD was confirmed in our study, and body weight controlling would reduce the incidence of CVD in Chinese males.

Generally speaking, using prevalence rates of these risk factors 20 year ago to estimate PARs of risk factors might be influenced by the changing of prevalence rates in this population. However, the PAR estimates using the risk factor levels of urban men in the National Health and Nutrition Survey 2002 were lower than expected. Compared with our results, the most difference was the PAR for hypercholesterolemia. Because the prevalence rate of hypercholesterolemia was only $3.7 \%$ in that national survey, it would obviously underestimate individual's number in our study $(17.6 \%)$ if using the prevalence of the survey 2002. Other risk factors prevalence was also higher than that in national survey 2002 (hypertension, $31.7 \%$ vs. $20.2 \%$, smoking $73.4 \%$ vs. $51.7 \%$, overweight $35.0 \%$ vs. $31.1 \%$ ). Considering the higher living standard in Beijing, it is reasonable that the prevalence of CVD risk factors in our cohort advanced the average levels in China. Therefore, the PARs derived from our study have much more practical significance.

\section{Limitations}

Some limitations of our study should be noted. Although prospective and with a long follow-up time, the Beijing Iron and Steel cohort study is workplace based and therefore not necessarily representative of the general population. After the 1978 economic reforms, China has experienced very rapid economic growth. The consequent improvement in living conditions, nutrition, and health care in the past several decades would affect risk factor levels and result in epidemiologic transition of diseases pattern. Though we have used the risk factor levels of urban men in the National Health and Nutrition Survey 2002 to calculate the PARs, it should be caution when applied those results into the general population. In addition, our cohort was restricted with very limited number of diabetes, and total cholesterol alone was measured because high density lipoprotein (HDL) cholesterol test was not widely used in China during the 1980s. Thus, the impacts of diabetes and HDL cholesterol on cardiovascular disease risk could not be assessed.

\section{Conclusions}

Our prospective data demonstrates that hypertension, cigarette smoking, overweight, hypercholesterolemia, are major risk factors for CVD. Hypertension and Cigarette smoking are the leading predictive parameter for CVD in Chinese male adults, and the association between blood pressure and CVD in Chinese is stronger than in Caucasians. To reduce incidence of CVD in Chinese 
males, continued strengthening of programs for prevention and intervention on these risks is needed.

\section{Acknowledgements}

This work was supported by a grant [2006BAI01A01] from the Ministry of Science and Technology, Beijing, China, and by a grant [D08050700320801] of Biomedical Project from the Beijing Municipal Council of Science and Technology, Beijing, China.

\section{Author details}

'Department of Evidence Based Medicine, Cardiovascular Institute and Fu Wai Hospital, Chinese Academy of Medical Sciences and Peking Union Medical College, Beijing, China. ${ }^{2}$ Cardiovascular Institute and Fu Wai Hospital, Chinese Academy of Medical Sciences and Peking Union Medical College, Beijing, China.

\section{Authors' contributions}

$J J$ analysed the data and drafted the manuscript. EP, JC, JL, JC, DS, DG, XW, $\mathrm{XD}$ and $\mathrm{JH}$ conducted the investigation and participated in discussing. JH supervised the project and revised the manuscript. All authors read and approved the final manuscript.

\section{Competing interests}

The authors declare that they have no competing interests.

Received: 18 February 2011 Accepted: 25 June 2011

Published: 25 June 2011

\section{References}

1. He J, Gu D, Wu X, Reynolds K, Duan X, Yao C, Wang J, Chen CS, Chen J, Wildman RP, Klag MJ, Whelton PK: Major causes of death among men and women in China. N Engl J Med 2005, 353(11):1124-1134.

2. Lopez AD, Mathers CD, Ezzati M, Jamison DT, Murray CJ: Global and regional burden of disease and risk factors, 2001: systematic analysis of population health data. Lancet 2006, 367(9524):1747-1757.

3. Anderson KM, Odell PM, Wilson PW, Kannel WB: Cardiovascular disease risk profiles. Am Heart J 1991, 121(1 Pt 2):293-298.

4. Lloyd-Jones DM, Wilson PWF, Larson MG, Beiser A, Leip EP, D'Agostino RB, Levy D: Framingham risk score and prediction of lifetime risk for coronary heart disease. The American Journal of Cardiology 2004, 94(1):20-24.

5. Wu Z, Yao C, Zhao D, Wu G, Wang W, Liu J, Zeng Z, Wu Y: Sino-MONICA project: a collaborative study on trends and determinants in cardiovascular diseases in China, Part i: morbidity and mortality monitoring. Circulation 2001, 103(3):462-468.

6. Wang W, Zhao D, Sun JY, Wang WH, Cheng J, Liu J, Qin LP, Liu S, Wu ZS: Risk factors comparison in Chinese patients developing acute coronary syndrome, ischemic or hemorrhagic stroke: a multi-provincial cohort study. Zhonghua Xin Xue Guan Bing Za Zhi 2006, 34(12):1133-1137.

7. Zhang XF, Attia J, D'Este K, Yu XH, Wu XG: Prevalence and magnitude of classical risk factors for coronary heart disease in a cohort of 4400 Chinese steelworkers over 13.5 years follow-up. Eur J Cardiovasc Prev Rehabil 2004, 11(2):113-120.

8. Zhang XF, Attia J, D'Este C, Yu XH: Prevalence and magnitude of classical risk factors for stroke in a cohort of 5092 Chinese steelworkers over 13.5 years of follow-up. Stroke 2004, 35(5):1052-1056.

9. Chen C, Lu FC: The guidelines for prevention and control of overweight and obesity in Chinese adults. Biomed Environ Sci 2004, 17(Suppl):1-36.

10. The WHO Global Database on Body Mass Index. [http://apps.who.int/bmi/ index.jsp?introPage $=$ intro_3.html].

11. Hippisley-Cox J, Coupland C, Vinogradova Y, Robson J, Minhas R, Sheikh A, Brindle P: Predicting cardiovascular risk in England and Wales: prospective derivation and validation of QRISK2. BMJ 2008, 336(7659):1475-1482.

12. Kahn H, Sempos C: Statistical methods in epidemiology Oxford University Press, USA; 1989

13. Wang LD: China National Nutrition and Health Survey 2002, Part 1: general report. People's medical Press, China; 2007.
14. Li LM, Rao KQ, Kong LZ, Yao CH, Xiang HD, Zhai FY, Ma GS, Yang XG: A description on the Chinese national nutrition and health survey in 2002. Zhonghua Liu Xing Bing Xue Za Zhi 2005, 26(7):478-484.

15. Dawber TR, Moore FE, Mann GV: Coronary heart disease in the Framingham study. Am J Public Health Nations Health 1957, 47(4 Pt 2):4-24.

16. Wu Y, Liu X, Li X, Li Y, Zhao L, Chen Z, Rao X, Zhou B, Detrano R, Liu K: Estimation of 10-year risk of fatal and nonfatal ischemic cardiovascular diseases in Chinese adults. Circulation 2006, 114(21):2217-2225.

17. Liu J, Hong Y, D'Agostino RB, Wu Z, Wang W, Sun J, Wilson PW, Kannel WB, Zhao D: Predictive value for the Chinese population of the Framingham CHD risk assessment tool compared with the Chinese Multi-Provincial Cohort Study. JAMA 2004, 291(21):2591-2599.

18. Assmann G, Cullen P, Schulte H: The Munster Heart Study (PROCAM). Results of follow-up at 8 years. Eur Heart J 1998, 19(Suppl A):A2-11.

19. Hippisley-Cox J, Coupland C, Vinogradova Y, Robson J, May M, Brindle P. Derivation and validation of QRISK, a new cardiovascular disease risk score for the United Kingdom: prospective open cohort study. BMJ 2007, 335(7611):136-148.

20. Group PRC-USCaCER: An epidemiological study of cardiovascular and cardiopulmonary disease risk factors in four populations in the People's Republic of China. Baseline report from the P.R.C.-U.S.A. Collaborative Study. Circulation 1992, 85(3):1083-1096.

21. Kelly TN, Gu D, Chen J, Huang JF, Chen JC, Duan X, Wu X, Chen CS, He J: Cigarette smoking and risk of stroke in the chinese adult population. Stroke 2008, 39(6):1688-1693.

22. Gu D, Kelly TN, Wu X, Chen J, Duan X, Huang JF, Chen JC, Whelton PK, He J: Blood pressure and risk of cardiovascular disease in Chinese men and women. Am J Hypertens 2008, 21(3):265-272.

23. Research ESCHDC: Blood pressure, cholesterol, and stroke in eastern Asia. The Lancet 1998, 352(9143):1801-1807.

24. Sesso HD, Stampfer MJ, Rosner B, Hennekens CH, Gaziano JM, Manson JE, Glynn RJ: Systolic and diastolic blood pressure, pulse pressure, and mean arterial pressure as predictors of cardiovascular disease risk in Men. Hypertension 2000, 36(5):801-807.

25. Glynn RJ, Chae CU, Guralnik JM, Taylor JO, Hennekens CH: Pulse pressure and mortality in older people. Arch Intern Med 2000, 160(18):2765-2772.

26. Franklin SS, Larson MG, Khan SA, Wong ND, Leip EP, Kannel WB, Levy D: Does the relation of blood pressure to coronary heart disease risk change with aging? The Framingham Heart Study. Circulation 2001, 103(9):1245-1249.

27. Franklin SS, Khan SA, Wong ND, Larson MG, Levy D: Is Pulse Pressure Useful in Predicting Risk for Coronary Heart Disease?: The Framingham Heart Study. Circulation 1999, 100(4):354-360.

28. Domanski M, Mitchell G, Pfeffer M, Neaton JD, Norman J, Svendsen K, Grimm R, Cohen J, Stamler J: Pulse pressure and cardiovascular diseaserelated mortality: follow-up study of the Multiple Risk Factor Intervention Trial (MRFIT). JAMA 2002, 287(20):2677-2683.

29. Gu D, Kelly TN, Wu X, Chen J, Samet JM, Huang JF, Zhu M, Chen JC, Chen CS, Duan X, Klag MJ, He J: Mortality attributable to smoking in China. N Engl J Med 2009, 360(2):150-159.

30. D'Agostino RB Sr, Vasan RS, Pencina MJ, Wolf PA, Cobain M, Massaro JM, Kannel WB: General cardiovascular risk profile for use in primary care: the Framingham Heart Study. Circulation 2008, 117(6):743-753.

31. Erhardt L: Cigarette smoking: an undertreated risk factor for cardiovascular disease. Atherosclerosis 2009, 205(1):23-32.

32. He J, Gu D, Reynolds K, Wu X, Muntner P, Zhao J, Chen J, Liu D, Mo J, Whelton PK: Serum total and lipoprotein cholesterol levels and awareness, treatment, and control of hypercholesterolemia in China. Circulation 2004, 110(4):405-411.

33. Collins R, Armitage J, Parish S, Sleight P, Peto R: Effects of cholesterollowering with simvastatin on stroke and other major vascular events in 20536 people with cerebrovascular disease or other high-risk conditions. Lancet 2004, 363(9411):757-767.

34. De Backer G, Ambrosioni E, Borch-Johnsen K, Brotons C, Cifkova R, Dallongeville J, Ebrahim S, Faergeman O, Graham I, Mancia G, Cats VM, Orth GK, Perk J, Pyorala K, Rodicio JL, Sans S, Sansoy V, Sechtem U, Silber S, Thomsen T, Wood D: European guidelines on cardiovascular disease prevention in clinical practice: third joint task force of European and other societies on cardiovascular disease prevention in clinical practice 
(constituted by representatives of eight societies and by invited experts). Eur J Cardiovasc Prev Rehabil 2003, 10(4):S1-S10.

35. Orford JL, Sesso HD, Stedman M, Gagnon D, Vokonas P, Gaziano JM: A comparison of the Framingham and European Society of Cardiology coronary heart disease risk prediction models in the normative aging study. Am Heart J 2002, 144(1):95-100.

36. Wang ZW, Wu YF, Zhao LC, Li Y, Yang J, Zhou BF: Trends in prevalence, awareness, treatment and control of hypertension in middle-aged Chinese population. Zhonghua Liu Xing Bing Xue Za Zhi 2004, 25(5):407-411.

37. Shiwaku K, Anuurad E, Enkhmaa B, Kitajima K, Yamane Y: Appropriate BMI for Asian populations. Lancet 2004, 363(9414):1077.

38. Zhou B: Predictive values of body mass index and waist circumference to risk factors of related diseases in Chinese adult population. Zhonghua Liu Xing Bing Xue Za Zhi 2002, 23(1):5-10.

\section{Pre-publication history}

The pre-publication history for this paper can be accessed here: http://www.biomedcentral.com/1471-2458/11/497/prepub

doi:10.1186/1471-2458-11-497

Cite this article as: Ji et al:: Classical risk factors of cardiovascular disease among Chinese male steel workers: a prospective cohort study for 20 years. BMC Public Health 2011 11:497.

\section{Submit your next manuscript to BioMed Central} and take full advantage of:

- Convenient online submission

- Thorough peer review

- No space constraints or color figure charges

- Immediate publication on acceptance

- Inclusion in PubMed, CAS, Scopus and Google Scholar

- Research which is freely available for redistribution

Submit your manuscript at www.biomedcentral.com/submit 